\title{
Analysis of the supply-demand status of China's natural gas to 2020
}

\author{
MA Yifei* and LI Yanli \\ School of Business Administration, China University of Petroleum, Beijing 102249, China \\ (C) China University of Petroleum (Beijing) and Springer-Verlag Berlin Heidelberg 2010
}

\begin{abstract}
The reserves, distribution, production and utilization of natural gas resources in China are introduced in this paper which leads a point of view that China's natural gas resources are relatively rich while distributed unevenly. The future production and consumption of China's natural gas are predicted using the Generalized Weng model and the Gray prediction model. The prediction suggests that with the increasing gas consumption China's natural gas production will not meet demand after 2010. In order to ease the supply-demand gap and realize rational development and utilization of China's natural gas resources, this paper puts forward some measures, such as using advanced technologies for natural gas development, establishing a long-distance pipeline network to rationalize the availability of natural gas across China and importing foreign natural gas and liquid natural gas (LNG).
\end{abstract}

Key words: Natural gas resources, natural gas production, natural gas consumption, generalized Weng's Model

\section{Introduction}

\subsection{The status of China's natural gas resources}

The development and use of natural gas as a clean fuel has become a worldwide issue. The preliminary statistics from the Ministry of Land and Resources of China in 2006 show that the remaining recoverable reserves of conventional natural gas reach 2.449 trillion cubic meters (LIN, 2007). China is relatively rich in total natural gas resources but actually very poor in per-capita terms. Distribution of natural gas resources in China is outlined below:

(1) Unbalanced distribution in the regions and basins

Natural gas in China is widely distributed but is mainly located in the middle-west of China and concentrated in a small number of large-scale oil- and gas-bearing basins, including Tarim, Ordos, Sichuan and the Orioles. The recoverable natural gas resources of these four basins account for three-quarters of China's total endowment.

(2) Small-scale of gas fields except for a few world-class scale fields

In China, only a few gas fields are regarded as large-scale gas fields, such as the Kela-2 gas field in the Tarim Basin, the Changqing and Sulige gas fields in the Ordos Basin, as well as the Puguang, Cangxi and Longgang gas fields in the Sichuan Basin.

(3) Low abundance of gas reserves, difficult production, and low efficiency.

*Corresponding author. email: mayifeima@126.com Received June 1, 2009

\subsection{Situation of production and utilization of China's natural gas}

Development of the natural gas industry in China started very late, and the natural gas resource is mainly located in the middle-west region of China that is far from the consumer market in East China. In recent years, China's natural gas output has increased steadily, but the increase is not large. In the primary energy consumption structure, the proportion of natural gas is low (Table 1).

With the enormous demand for cleaner energy to improve the urban environment, China's natural gas industry is developing rapidly. Both CNPC and SINOPEC have chosen natural gas as one of the key strategic development areas. CNOOC is also increasing its investment in liquid natural gas (LNG) import projects. All the above indicates a promising future for China's natural gas industry.

Table 1 China's primary energy consumption structure in 2006 and 2007(\%)

\begin{tabular}{cccccc}
\hline Years & Oil & Natural gas & Coal & Nuclear power & Water power \\
\hline 2006 & 20.6 & 2.95 & 70.2 & 0.7 & 5.55 \\
2007 & 19.7 & 3.25 & 70.42 & 0.76 & 5.87 \\
\hline
\end{tabular}

Sources: BP. Statistical Review of World Energy 2008

\subsection{Significance to keep the balance between the supply and demand of China's natural gas}

The rapid development of the economy and the 
requirement of environment protection in China is creating an increasing demand for clean energy. In recent years, The development of large-scale natural gas fields have been gradually increasing, with examples including the Sichuan, Changqing and Tarim Basin gas fields.

Long-distance pipeline construction is continuing. The West-East Gas Transmission Project, Line One, was commissioned on October 1st, 2004. The pipeline goes across the country from the Lunnan Oilfield, Tarim Basin, NW China to Lanzhou (Gansu province), Xi'an (Shaanxi province), Luoyang (Henan province) and reaches Shanghai in east China. Line Two is under construction from Horgos (Xinjiang Uygur Autonomous Region) to Guangzhou (Guangdong province) and Shanghai. It will be $4859 \mathrm{~km}$ long and go through 13 provinces and autonomous regions. Line Three is being planned.

From the above discussion, it is clear that with the discovery of gas fields in West China and the construction of West-East Gas Pipelines, China's natural gas industry has entered a period of rapid development. However, it should be noted that the investment is so great both in long-distance pipelines and gas exploration that a long-term operation at full capacity is necessary to recover the investment. The power generation and fertilizer projects downstream need great investment, and the urban environment also requires long-term stable supply of natural gas. In addition, the natural gas supply is also responsible for the sustainable development of China's economy. Therefore, it is important for China's natural gas to keep supply and demand approximately in balance. This paper predicts the yields and consumption of natural gas in China up to 2020, and estimates the gap between supply and demand and alerts decision-makers to the need to take measures to prevent supply shortfalls and to ensure a smooth supply of natural gas.

\section{Forecast of China's natural gas outputs}

There are a variety of models for forecasting the natural gas outputs, such as the Hubbert model (Hubbert, 1949; 1967), HCZ forecast model(HU et al, 1995), the generalized Weng model(CHEN et al,1996). In many impact factors, HCZ model only takes the time factor into account, so it is excluded in this paper. Hubbert's model was developed and proved by a well-known American geologist, based on a large number of experiments and empirical practices (Hubbert, 1949; 1967). The use of this Hubbert model in this paper has some limitations; the predicted outputs are generally greater than actual outputs and the prediction results are less accurate with time. So it is excluded too. Weng's model is generalized by Professor CHEN Yuanqian in 1996 (CHEN et al,1996). It is characterized by fast increase in production output but low decline. The generalized Weng model is a typical model for predicting the outputs of oil and gas fields and its accuracy in prediction has been confirmed (GAO and CHEN, 2002), Therefore, it is chosen in this paper for quantitative forecast and analysis of natural gas production in the future.

From the generalized Weng forecast model (CHEN and HU, 1996)

$$
\frac{Q}{t^{b}}=a e^{-(t / c)}
$$

where $Q$ is the annual production of gas fields; $t$ is the time, year; and $a, b, c$ are the parameters of the model.

Get logarithm on the both sides: $\ln \left(\frac{Q}{t^{b}}\right)=\ln a+(-t / c)$

Let $\alpha=\ln a, \beta=-1 / c$,

then $\ln \left(\frac{Q}{t^{b}}\right)=\alpha+\beta t$

With the linear iterative method, and using a series of $b$ values and actual production data, the best fitted $b$, at which the predicted outputs of natural gas have the highest correlation coefficient with the actual historical production data, could be obtained. It is the desired $b$ value. At this time, the linear regression method was used, and the intercept $\alpha$ and slope $\beta$ were obtained, hence the values of a and c could be obtained.

We use Eq. (2) and the actual production data to produce a linear equation group with Linear interpolation, and with the above method, we obtain $b=1.1024$, at which the correlation coefficient, $R=98.4 \%$, between the predicted outputs and the actual production data; By the linear regression method, intercept $\alpha=0.7229$ and slope $\beta=0.0778$ were obtained. By the formula: $\alpha=\operatorname{lna}, \beta=-1 / c$, we could get $a=2.060$, $c=-12.87$. Substituting the values of the three parameters, $a, b, c$, for Eq.(1), the annual natural gas production can be predicted. Table 2 is the gas production forecast data based on the generalized Weng model.

Table 2 Prediction of China's annual gas production using Weng's model

\begin{tabular}{c|cccccc}
\multicolumn{1}{c}{} & \multicolumn{5}{c}{ (unit: 100 million cubic meters) } \\
\hline Years & 2009 & 2010 & 2011 & 2012 & 2013 & 2014 \\
Production & 803 & 901 & 1010 & 1130 & 1264 & 1412 \\
\hline Years & 2015 & 2016 & 2017 & 2018 & 2019 & 2020 \\
Production & 1575 & 1756 & 1956 & 2178 & 2422 & 2692 \\
\hline
\end{tabular}

Table 2 shows that from 2009 to 2020 , the annual natural gas production would increase steadily. The predicted production is also shown in Fig. 1. And Fig. 1 shows an obvious upward trend of annual natural gas production in the future, indicating that the production of natural gas in the future would increase with the further development of economy.

\section{Forecast of China's natural gas consumption}

Naim and Darwish (1998) showed that natural gas consumption and gross domestic product (GDP) were correlated. XU (2005) used the gray system theory to successfully predict the oil consumption. Therefore, this paper chooses the gray system theory to establish a bivariate model of gray system GM $(1,2)(\mathrm{DENG}, 1987)$ between the 
natural gas consumption and gross domestic product (GDP), and quantitatively study the demand trend of China's natural gas consumption. Since GDP has a certain independence, the GM $(1,1)$ model of GDP is firstly established, then based on the GM $(1,1)$ model, GM $(1,2)$ model with GDP and natural gas consumption demand is built.

Based on the Gray system model GM $(1,2)$, China's gas consumption in 2009-2020 was predicted and the results are shown in Table 4 using seven years' GDP data and the actual natural gas consumption from 2001 to 2007 as input data (see Table 3).

It can be seen that the domestic natural gas consumption of China will increase ever more rapidly in the future.

Table 3 Statistics of China's GDP and actual gas consumption during 2001-2008

\begin{tabular}{ccc}
\hline Years & $\begin{array}{c}\text { GDP } \\
(100 \text { million yuan })\end{array}$ & $\begin{array}{c}\text { Consumption } \\
(100 \text { million cubic meters })\end{array}$ \\
\hline 2001 & 109655 & 274 \\
2002 & 120332 & 292 \\
2003 & 135822 & 339 \\
2004 & 159878 & 397 \\
2006 & 183217 & 468 \\
2007 & 211923 & 561 \\
2008 & 249529 & 673 \\
\hline
\end{tabular}

Sources: China Statistical Yearbook 2001-2008, (BP. Statistical Review of World Energy 2008)

Table 4 Forecast of gas consumption in China using the Gray system model (unit: 100 million cubic meters)

\begin{tabular}{c|cccccc}
\hline Years & 2009 & 2010 & 2011 & 2012 & 2013 & 2014 \\
Consumption & 900 & 1043 & 1208 & 1400 & 1623 & 1881 \\
\hline Years & 2015 & 2016 & 2017 & 2018 & 2019 & 2020 \\
Consumption & 2180 & 2526 & 2928 & 3393 & 3933 & 4558 \\
\hline
\end{tabular}

\section{Analysis of China's future natural gas supply-demand gap}

In order to achieve sustainable development and utilization of China's natural gas resources, a quantitative comparison is done between the future gas consumption and production (see Table 5 and Fig. 1).

Table 5 and Fig. 1 shows that China's natural gas supplydemand gap will grow increasingly with time in the future, and result in a substantial shortage of supply.
Table 5 Comparison of predicted gas production and consumption in China (unit: 100 million cubic meters)

\begin{tabular}{|c|c|c|c|}
\hline Years & Consumption & Product & Supply-demand gap \\
\hline 2009 & 899 & 803 & 96 \\
\hline 2010 & 1042 & 901 & 141 \\
\hline 2011 & 1208 & 1010 & 198 \\
\hline 2012 & 1400 & 1130 & 269 \\
\hline 2013 & 1622 & 1264 & 358 \\
\hline 2014 & 1880 & 1412 & 468 \\
\hline 2015 & 2179 & 1575 & 604 \\
\hline 2016 & 2526 & 1756 & 769 \\
\hline 2017 & 2927 & 1957 & 970 \\
\hline 2018 & 3393 & 2178 & 1215 \\
\hline 2019 & 3932 & 2422 & 1510 \\
\hline 2020 & 4557 & 2692 & 1865 \\
\hline
\end{tabular}

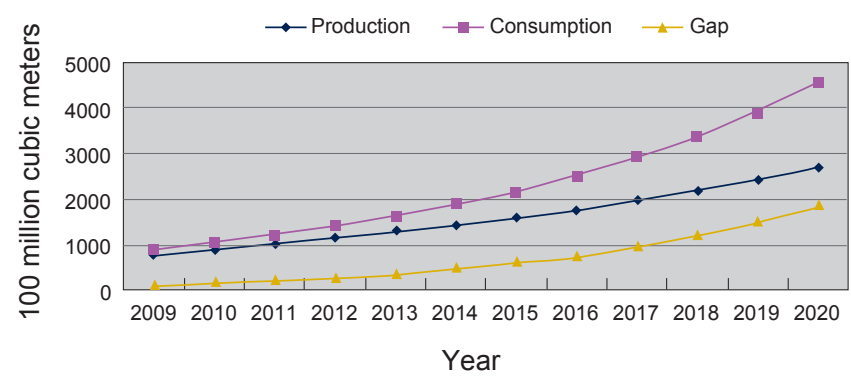

Fig. 1 China's gas production/consumption/gap forecast

Taking the predicted supply of natural gas in 2010 and 2020 as an example, the status of supply-demand will be:

(1) in 2010

According to the forecast of production and consumption of China's natural gas, the production of China's natural gas in 2010 would be the $901 \times 10^{8} \mathrm{~m}^{3}$, while the demand would be $1,043 \times 10^{8} \mathrm{~m}^{3}$, which would result in a gap of $141 \times 10^{8} \mathrm{~m}^{3}$. (2) in 2020

According to the forecast of production and consumption of China's natural gas, the production in 2020 would be $2,692 \times 10^{8} \mathrm{~m}^{3}$, while the demand would be $4,558 \times 10^{8} \mathrm{~m}^{3}$, which would result in a gap of $1,865 \times 10^{8} \mathrm{~m}^{3}$.

\section{Conclusion and suggestions}

In this paper, the production and consumption of China's natural gas in the future are predicted by using the Generalized Weng Model and the Gray prediction model. The results show that the shortfall in natural gas supply is expected to reach 14 billion cubic meters in 2010 and even more than 180 billion cubic meters in 2020. In other words, 
if the government fail to take some effective measures to encourage the development and import of natural gas or if it rashly launches new high natural gas consuming projects, the demand for natural gas would be certain to exceed supply in the future. For this reason, some suggestions on solving the big shortfall of natural gas supply are given as follows:

\section{(1) Developing long-distance pipeline network system}

Natural gas is a non-renewable resources and a individual gas field will move towards the depletion with exploitation. The long-distance gas pipeline network system can ensure gas supply even if a certain gas field is closed or the gas from a country is disrupted.

\section{(2) Adjusting natural gas utilization trends with price levers}

The lever of price should be used to encourage investment on those projects that help pollution abatement, such as civilian use, urban heating and gas-fueled vehicle projects. On the other hand, the power generation projects and fertilizer projects should be strictly limited; encourage to use hydro-electric power generation and nuclear power in stead of gas power generation; and increase the import of chemical fertilizer. This guarantees that the limited natural gas resources are used in improving the environment.

\section{(3) Increasing the import of natural gas and LNG}

Importing natural gas and LNG is an effective way to supplement domestic natural gas resources. China's attempt to import natural gas and LNG has been proved to be successful. For example, Line Two of the West-East Gas transportation project will import natural gas from Turkmenistan. Besides, CNOOC has signed several LNG projects with foreign companies, including the Shenzhen Dapeng LNG project with Australia, the Fujian LNG project with Indonesia and the Shanghai and Zhejiang LNG project with Malaysia.

\section{References}

BP. Statistical Review of World Energy 2008. http://www.bp.com/ productlanding.do? categoryId $=6929 \&$ contentId $=7044109$

CHEN Y Q and HU J G. Weng's model for review and the new derived. China's Offshore Oil and Gas (Geology). 1996. 10 (05): 317-324 (in Chinese)

CHEN Q, JIAN G H and ZHANG D J. Logistic model derivation and application. Xinjiang Petroleum Geology. 1996. 17 (2): 150-155 (in Chinese)

DENG J L. The Basic Method of Gray System. Wuhan: Huazhong University of Science and Technology Publishing House. 1987 (in Chinese)

GAO R Q and Chen Y Q. Forecast of our oil resources. Petroleum Journal. 2002. 23(05): 44-48 (in Chinese)

Hubbert M K. Energy from fossil fuels. Science. 1949. 109(2823): 103109

Hubbert M K. Degree of advancement of petroleum exploration in the United States. AAPG Bulletin.1967. 52(11): 2207-2227

HU J G, CHEN Y Q and ZHANG Z S. A new model for Forecast oil and gas production and recoverable reserves. Journal of Oil. 1995. 16 (1): 79-86 (in Chinese)

LIN W. Natural gas discovery will trigger industrial change in the situation. China Securities Journal. May 28. 2007(A03) (in Chinese)

Naim A and Darwish A G. Sustainable energy development. Renewable and Sustainable Energy Reviews. 1998. (2): 125-133

XU R S. China's oil demand forecast research based on gray system Theory. The International Oil Economy. 2005. 13(04): 36-38 (in Chinese) 